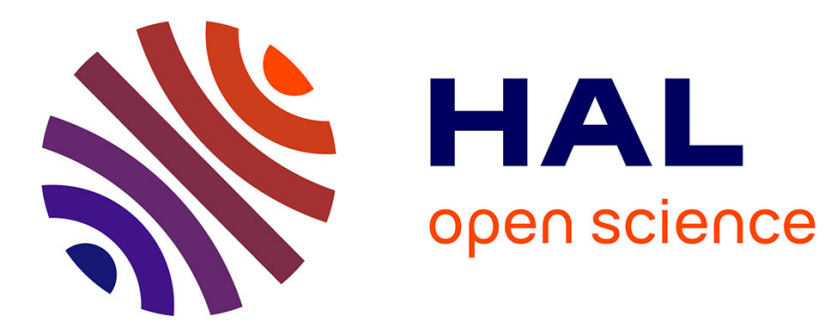

\title{
Coordinating Free Improvisation: An Integrative Framework for the Study of Collective Improvisation Pierre Saint Germier, Clément Canonne
}

\section{To cite this version:}

Pierre Saint Germier, Clément Canonne. Coordinating Free Improvisation: An Integrative Framework for the Study of Collective Improvisation. Musicae Scientiae, 2020, 10.1177/1029864920976182 . hal03053405

\section{HAL Id: hal-03053405 \\ https://hal.science/hal-03053405}

Submitted on 11 May 2021

HAL is a multi-disciplinary open access archive for the deposit and dissemination of scientific research documents, whether they are published or not. The documents may come from teaching and research institutions in France or abroad, or from public or private research centers.
L'archive ouverte pluridisciplinaire HAL, est destinée au dépôt et à la diffusion de documents scientifiques de niveau recherche, publiés ou non, émanant des établissements d'enseignement et de recherche français ou étrangers, des laboratoires publics ou privés. 


\title{
Coordinating free improvisation: An integrative framework for the study of collective improvisation
}

\author{
Pierre Saint-Germier ${ }^{1}$ and Clément Canonne ${ }^{1 *}$ \\ 1 - STMS UMR 9912 (CNRS/IRCAM/SU), Paris, France \\ * corresponding author: clementcanonne@ hotmail.com
}

Keywords: Improvisation, Joint action, Coordination, Interaction, Communication 
Coordinating free improvisation:

An integrative framework for the study of collective improvisation 


\begin{abstract}
Understanding how musicians can coordinate their musical actions when they improvise together remains an important theoretical and empirical challenge. In this paper, we suggest a broad theoretical framework, compatible with up-to-date research on joint action, which can account for coordination in collective improvisation, especially in the hard case of so-called collective free improvisation. This framework addresses the limits of an account of coordination in collective improvisation that relies only on low-level, emergent coordination mechanisms, and shows how these mechanisms can be combined with planned coordination mechanisms to explain how improvisers deal with some of the main coordination problems that typically arise in collectively improvised performances. As such, our framework allows for the formulation of new hypotheses that pave the way for further empirical investigations on collective improvisation and sheds light on collectively improvised behavior at large.
\end{abstract}


Understanding how musicians can improvise together seems to be at the crossroads of two distinct blind spots. On the one hand, and despite some recent efforts (Wilson \& MacDonald, 2012, 2016, 2017; Moran et al., 2015; Canonne \& Aucouturier, 2016; Aucouturier \& Canonne, 2017; Pras et al., 2017; Hadley et al., 2018; Wöllner, 2020), empirical research on the cognition of musical improvisation has mainly tried to understand the mechanisms that underpin the generation of individual improvised behaviors (Ashley, 2016). On the other hand, research on joint action has mainly focused on scripted forms of joint actions, trying to shed light on the mechanisms that allow agents to coordinate with each other by relying on score-based musical paradigms (e.g., Wolf et al., 2018; MacRitchie et al., 2018; Loehr \& Vesper, 2016). As a result, the coordination of joint action in improvised musical performances still cries out for an explanation. Such an explanation means bringing together improvisation studies with joint action research, and this is precisely what we aim to do in the present paper.

We choose here to approach the issue of coordination in collective improvisation through the lens of so-called collective free improvisation (or CFI for short) (Bailey, 1992; Corbett, 2016). Two reasons motivate this choice. First, a valid explanation of how musicians coordinate their actions when they improvise together should be able to accommodate hard cases such as the ones provided by CFI, in which musicians have arguably no script at all to follow. Second, and drawing on the well-established idea that improvisational practices lie on a continuum (Nettl, 1974; Pressing, 1984), the coordination problems that appear in CFI in their purest form are likely to be present, although to a lesser extent, in other kinds of improvisational practices, in addition to their own specific coordination problems (e.g., collectively maintaining a groove, playing a theme together in a rubato-like fashion, avoiding harmonic clashes, etc.).

Our main goal in this paper is to describe a broad theoretical framework, compatible with up-to-date research on joint action, which can account for coordination in CFI by integrating into a coherent whole the existing pieces of empirical research that have been published on CFI over the years. After offering a characterization of CFI, we will introduce our general approach to coordination, and show how it can be applied to CFI. We will then assess the explanatory powers and limits of low-level emergent coordination mechanism, and argue that locally compatible goals also can play a role in 
the coordination of CFI. Finally, we will conclude the discussion with possible empirical investigations enabled by this framework, as well as generalizations to other kinds of collectively improvised behavior inside and outside of music.

\section{Collective Free Improvisation and its coordination problems}

\section{Collective Free Improvisation: a first approach}

CFI is notoriously difficult to define. If understood to refer to collective improvisation out of nothing, then CFI is arguably a myth. This does not mean however that there is no way to characterize this musical genre that illuminates how it differs from other kinds of collective musical improvisation.

First, CFI can be characterized as referent-free improvisation. According to Pressing (1984), a referent is "an underlying formal scheme or guiding image specific to a given piece, used by the improviser to facilitate the generation and editing of improvised behavior on an intermediate timescale" (Pressing, 1984, p. 346). Songs, themes, motives, harmonic progressions, or scales can be taken as referents for collective improvisation, so long as they are used as the basis for the generation of a musical content in the course of performance, in a particular situation. In referent-based collective improvisation, the referent is usually common knowledge among the participants, that is, everyone knows that everyone knows which referent is being used, which greatly helps coordination. CFI performers, in contrast, choose to improvise without a referent. Instead of explicitly agreeing on some structure before they start to play, they leave the direction of the music to choices made only in the course of performance. This does not mean, again, that CFI is made out of nothing. It is just that the various materials and resources that can be used by the performers are left open and implicit (thus allowing for a large amount of dissensus and negotiation in the performance). These can include anything from specific sonic elements to global aesthetic frameworks (Canonne, 2018), which constrain the process of collective improvisation, but not by coordinating the development of an improvisation at an intermediate time-scale, as referents typically do. 
Second, CFI can be characterized as non-idiomatic improvisation. According to Derek Bailey,

idiomatic improvisation, the most widely used, is mainly concerned with the expression of an idiom - such as jazz, flamenco or baroque - and takes its identity and motivation from that idiom. Non-idiomatic improvisation has other concerns and is most usually found in so-called 'free' improvisation and, while it can be highly stylized, is not usually tied to representing an idiomatic identity. (Bailey, 1992, p. ix)

Again, to characterize CFI as non-idiomatic is not to deny that free improvisers can develop a more or less stable artistic identity over the years, which may amount to a fairly recognizable improvisational style. But this hardly amounts to anything like a general CFI idiom, understood as a shared lingua franca within the broad community of free improvisers, that would create common stylistic expectations, and that performers would explicitly and independently seek to express when freely improvising together. First, as part of a process of artistic singularization, improvisers generally develop a highly idiosyncratic stock of individual musical materials that are meant to be distinctive and are thus generally not shared at the broader level of the CFI community. As Arthurs puts it, CFI can be seen as "the real-time employment of a repertoire of individual, 'known' materials, in a predominantly 'unknown' and ever-changing group context' (Arthurs, 2016, p. 183). Of course, most enduring CFI ensembles come to develop a distinctive aesthetic identity over rehearsals and performances that shapes choices and expectations (Canonne, 2018). But free improvisers also play outside their long-standing groups, meeting new musicians on stage or during private sessions, making the group environment once again unpredictable, so that that an acquired familiarity cannot be the whole explanation of how CFI ensembles coordinate. Second, CFI is certainly not an aesthetically unified practice: the improvised music scene is widely diverse, with influences ranging from free jazz to noise music, European free music, post-Cagean indeterminacy, instrumental musique concrète, or drone music. While some musicians may choose to play within a given musical sub-niche only, many improvisers encounter, 
at least occasionally, polystylistic settings (Borgo, 2005; Arthurs, 2016; Burrows \& Reed, 2016), in which the implicit guidelines and aesthetic delineations are far from clear.

The absence of both a referent and a shared overarching idiom deprives CFI ensembles of two resources that usually prove crucial to the coordination of the collective performance in other forms of musical improvisation. This is what makes CFI such a hard case for the analysis of coordination in improvised joint actions.

\section{Coordination and its problems}

In the most general terms, a coordination problem occurs when a plurality of agents, with predominantly coincident preferences, need to take courses of actions whose outcomes depend on the actions of all the other agents. A solution to a coordination problem, then, takes the form of a specific type of equilibrium between the course of actions chosen by all the agents as a collective; a combination of individual actions, in the context of a coordination problem, forms a coordination equilibrium if and only if no agent would have reached a better outcome had that agent, or any other agent, acted otherwise (Lewis, 1969/2002).

For example, rowers on a boat face a coordination problem: they are all concerned with maximizing the speed of the boat, while minimizing their own effort. Their preferences predominantly coincide to the extent that the difference between the values ascribed by any two agents to the same outcome is generally small compared to the difference between each agent's ascriptions of value to alternative possible outcomes (Lewis 1969/2002, p. 14). For example, although a stronger rower might prefer a fast synchronized pace to a slower one, and a less strong rower a slightly slower pace, that difference is small compared to the difference in value, for each of them, between the case in which all the rowers row in synchrony and the case in which, say, half are in synchrony and half row randomly. And if all the rowers row in synchrony, say every tenth of a second, then their collective behavior reaches a coordination equilibrium: if just one rower rows just one twentieth of a second too early, the speed of the boat will be slightly less, for a slightly larger effort from all the rowers. 
A collective behavior can be said to be coordinated, then, to the extent that it approximates a solution to a coordination problem. Since coordination equilibria are idealizations that are hardly ever exactly realized in practice, it is sufficient for a collective behavior to count as coordinated if it comes close enough to coordination equilibrium. Seen from this angle, coordination is less a binary feature than a matter of degree. For instance, if all the rowers except one were to row in synchrony at the same frequency, it would still make sense to describe their collective behavior as coordinated, even though it would not be coordinated perfectly.

It is well known that a given coordination problem can be solved in different ways, by reaching one of several possible coordination equilibria, some of which may be more valuable than others. For example, a slightly higher frequency of collective synchronized rowing might allow a better balance between speed and effort, while a much higher frequency might yield a less favorable balance. Yet both count as equilibria, and thus both are equally coordinated. The difficulty of solving a coordination problem precisely consists in ensuring that all the agents converge towards the same equilibrium. The essential task of explaining coordination in a type of collective behavior is thus to (i) specify the kind of coordination problem it faces and (ii) the mechanisms by which agents can converge on the same solutions. And this is how we propose to approach coordination in CFI.

\section{Coordination problems in Collective Free Improvisation}

That musical performances in general raise coordination problems in the sense defined above should be obvious, as long as one understands the preferences of agents in a broad sense that encompasses the satisfaction of aesthetic, artistic, and emotional values. In the case of CFI, one might question the assumption of predominantly coinciding preferences, in light of the absence of a specific idiom and of the propensity of CFI performers to improvise successfully even with unfamiliar partners who do not necessarily share their specific aesthetic conceptions and values. This assumption, however, does allow for some amount of divergence in the valuation of possible outcomes. What it does rule out is that the difference in the valuation of the same outcome by two agents is often larger than the 
difference between the ways in which the same agents value distinct outcomes. In such situations, it simply does not make sense to describe agents as coordinating their actions, as they will too often disagree as to the value of their combined actions. So this condition of predominantly coincident or overlapping preferences can be seen as setting a limit to the amount of aesthetic dissensus that a successful CFI performance can tolerate (see Watson, 2004, for a discussion of this issue in the context of Company Weeks, Derek Bailey's famous improvisation festival).

When one applies the general framework reviewed above to a collective behavior as complex and multifaceted as a musical performance, it is more fruitful to see a given performance as raising a plurality of comparatively simpler and better-defined coordination problems, rather than a unique coordination problem, dealing simultaneously with all dimensions of musical performance. For example, a bebop ensemble playing a standard is best seen as facing a rhythmic coordination problem (when it comes to keeping a swinging tempo together), a harmonic coordination problem (when it comes to realizing the same abstract chord progression consistently), a formal coordination problem (when it comes to organizing the performance consistently into an exposition of the theme, a number of solos, a re-exposition, and an ending), and an expressive coordination problem (when it comes to distributing the expressivity of the performance consistently among the group members).

The number and character of such coordination problems are determined in a large part by the idiom under consideration, and in some cases by the referent used if it raises special coordination problems (e.g. Flamenco Sketches on Miles Davis's Kind of Blue, where the chord sequence is fixed, but not the duration of each chord). In CFI performances, which lack both, the identification of specific coordination problems is less straightforward. It might even be thought that coordination itself is less an issue than in other types of improvised music. However, to the extent that members of CFI ensembles favor an aesthetic balance between continuity and variety, so that the music navigates between the Scylla of ever-changing, unconnected ideas, and the Charybdis of ever-repeating, immutable ideas, they also face a formal coordination problem of organizing this balance throughout the duration of the performance. Even though there are no explicit idiomatic rules or conventions that prescribe how CFI performances can 
be formally organized, such performances are typically characterized by a "segmental form" (Nunn, 1998, p. 43), i.e., consisting in a succession of sequences, each having a stable musical identity of its own, separated by unstable transitions. This feature of CFI has been described by several analysts independently (Bertolani, 2019; Burrows \& Reed, 2016; Borgo, 2005; Canonne \& Garnier, 2012, 2015; Pelz-Sherman, 1998), and is perhaps the most obvious sort of emergent structure observable in CFI. For example, Canonne and Garnier (2015) showed that expert third-party listeners' segmentation of a series of trio improvisations were largely similar, meaning that the performances' sequential structure had a relatively high degree of transparency. Even though this segmental form is best viewed as emerging from the interactions of the performers, rather than being consciously and collectively intended by them, it is unlikely that such forms emerge by chance. In other words, those emergent segmental forms provide a type of solution to a general coordination problem that seems to require particular mechanisms to be effectively solved in the way it is.

The formal coordination problem faced by CFI performers that seek such a balance between continuity and variety can be decomposed into two sub-problems. On the one hand, when a new sequence starts, usually after a salient new musical idea is introduced, CFI performers face a problem of consolidation: establishing a more or less stable sonic and/or interactional framework that allows for collective exploration or development for a certain amount of time. On the other hand, when the consolidation of a sequence loses momentum, or starts to become unstable, CFI performers face a problem of articulation: moving from one sequence to a new one. As usual with coordination problems, there may be many possible coordination equilibria as solutions for each problem, as there may be many ways to consolidate a sequence, or articulate a transition between sequences, the difficulty for the group being to converge towards the same solution.

A passage from the quintet performance of Derek Bailey (guitar), Alexander Balanescu (violin), Vanessa Mackness (voice), Yves Robert (trombone) and John Zorn (alto saxophone) recorded during the 1991 edition of Company Weeks nicely illustrates the dynamics of articulation and consolidation in CFI (Bailey, Balanescu, Mackness, 
Robert, and Zorn, 1994) ${ }^{1}$ : at 1'53" a sequence characterized by a very high level of individual activity starts, with a progressive collective intensification which reaches its climax at 2'39', to the point that the level of energy created by the group appears difficult to sustain for a longer time. This translates into an articulation problem for the musicians: how to exit such a high-energy sequence? At this point (2'58'), Derek Bailey produces a contrasting Larsen sound that triggers the introduction of a new sequence with a lower level of energy overall. But now the musicians face a consolidation problem: all the musicians indeed seem to look tentatively for a new position within the group, trying different possibilities with different materials (tremolo, staccato chords, melodic motives, quasi-scales, etc.), as if they were trying to find a way for each of the five voices to mesh in a coherent polyphonic organization. At 3'19', the musicians finally find a new stable framework for their collective improvisation, slowing down the rhythm of their individual discourse and progressively introducing held sounds, thus reducing the polyphonic complexity of the output and converging on a structure that combines melodic fragments (mainly created by the voice and the violin) and an ever-changing harmonic background collectively produced by the held sounds of the musicians - a framework that will remain more or less stable until it dissolves into a collective silence at 4'15"'.

These mere two minutes of music are arguably typical of the two problems of consolidation and articulation that are routinely encountered in a CFI performance, and of the ability of seasoned improvisers to move collectively from one sequence to another. We do not claim that the consolidation and articulation problems exhaust all the coordination problems faced in CFI performance, but we take them as two of the most typical ones, as well as amenable to controlled description and empirical study. Having clarified what needs to be coordinated in CFI, we may now consider how coordination is effectively achieved in CFI.

\section{Emergent coordination in Collective Free Improvisation}

1

This performance can be heard here: https://soundcloud.com/user-146133067/dbabyrizvm-part1company-91/s-kLAzocRdsrg. 
It is common in the cognitive psychology literature (Knoblich et al., 2011; Butterfill, 2017) to distinguish two forms of coordination that require different kinds of explanation: "Planned coordination is coordination driven by a collective goal-state, whereas emergent coordination is coordination not so driven" (Butterfill, 2017, p. 74). In Butterfill's terminology, a collective goal-state is a combination of mental states that collectively represent a goal for a joint action. When Alice and Bob move the big table from their bedroom to their living room after counting "one, two, three," they achieve a joint outcome that is represented by a combination of mental states, involving Alice's mental state, for example the intention to grab the left side and push forwards, and Bob's mental state, for example the intention to grab the right side and pull backwards. In order to explain planned coordination, one needs to explain how this collective goal-state effectively guides the achievement of the outcome it represents by means of interdependent actions. Emergent coordination is defined negatively as coordination not driven by such a collective goal-state. What explains coordination, then, are mechanisms that only require an appropriate coupling between co-agents (Knoblich et al., 2011; Butterfill, 2017). In order to explain emergent coordination, one needs to explain how such couplings guide the autonomous achievement of a collective outcome by means of interdependent actions. The key to the explanation of emergent coordination, then, will be the way the coupled co-agents influence each other's behavior so that they interdependently perform a joint achievement.

Whereas performances of pre-composed, as well as performances of referentbased idiomatically improvised pieces, are clearly coordinated, at least in part, by virtue of such collective goal-states, this seems prima facie implausible in the case of CFI as, by definition, CFI performers do not agree on the outcome of their joint performance in advance. Let us first consider, then, how known emergent coordination mechanisms can explain how CFI performers solve their consolidation and articulation coordination problems.

\section{Emergent coordination mechanisms at work}


Knoblich et al. (2011) distinguish four types of emergent coordination mechanisms: entrainment, affordances, perception-action couplings involving common motor representations and motor simulation mechanisms. All of them have something to offer to the coordination of CFI musicians.

Entrainment is one source of spontaneous coordination of motor behavior observed in many familiar phenomena, such as the synchronization of clapping hands, rocking chairs, or the coordination of limbs in locomotion (within and across individuals). Unsurprisingly, entrainment is also known to play a role in collective music performance, including improvised music performance (Clayton, 2007; Phillips-Silver \& Keller, 2012). It should be emphasized that the absence of a clear meter or pulse in CFI does not prevent entrainment mechanisms from operating, as shown by Will et al. (2015) in the case of non-pulsed improvisation in Indian music. It is observed that in highly irregular sequences, such as the alap part of a raga, hearers tend to feel a pulse as a result of an entrainment to the perceived musical events, but that is predominantly shaped by their inner rhythmical periodicity and involves significant intersubjective differences. In more regular sequences, such as the jhor part, the felt pulses are predominantly shaped by the musical events and intersubjective differences decrease. This study deals only with pulses felt by hearers, so it is not straightforward to conclude that similar patterns hold for musicians. However, the fact that entrainment processes do operate even in musical practices that manifest a high temporal irregularity suggests that entrainment may favor coordination in CFI too. Entrainment mechanisms, insofar as they are directed towards synchronization, frequency-locking, or phase-locking, can contribute to the explanation of the consolidation of sequences of CFI performances. Even though the inner pulses felt by performers do not coincide, it is sufficient that they form a distinct pattern over time to create a sense of rhythmic identity over a given sequence. However, since entrainment mechanisms explain convergence, rather than divergence of behavior, they provide limited resources to explain the articulation of CFI performances.

Affordances (Gibson, 1979/2014) provide another type of emergent coordination mechanism that is helpful for the explanation of coordination in CFI. The affordance of an object or event can be defined as the possibilities of action it offers to the perceiving subject regarding the perceiving object or event. For example, a chair affords the action 
of sitting. What an object or event affords to an agent depends on the action repertoires of this agent. A log of wood obviously affords different actions to a man, on the one hand, and a colony of termites, on the other. This essential relationality of affordances is to be kept in mind, especially when we consider highly culturalized and socialized affordances in the human realm. The concept of affordance, initially introduced in the context of visual perception is clearly relevant to music perception (Clarke, 2005). Although most uses of the concept are related to the study of musical listening, it is also relevant for music-making (Davidson \& Good, 2002; Windsor \& De Bézenac, 2012), especially in the context of musical improvisation (Borgo 2005, 2007; Love, 2017). As Windsor and De Bézenac nicely put it: "The behaviours of interacting musicians are simultaneously motivated and constrained by the collectively produced actions and resulting sounds: what is seen, heard and felt affords particular kinds of subsequent behaviour" (2012, p. 111).

There are two ways in which affordances can explain coordination among a group of agents (Knoblich et al., 2011). An object is a common affordance if it affords the same thing to each agent in the group when perceived at the same time. For example, a sudden loud sound in the context of a sparse and quiet sequence affords to each improviser the opportunity to introduce some new material. Alternatively, an object or an event is a joint affordance if it affords a joint action for the group as a whole, as opposed to affording something to individual agents separately. Although the existence and properties of joint affordances have mostly been studied with respect to affordances for motor behaviors such as lifting or avoiding obstacles (Isenhower et al., 2010; Davis et al., 2010), and remain to be studied empirically for musical behavior, it is plausible that music offers joint affordances as well as common ones. For instance, serendipitous simultaneous hits in a non-pulsed sequence can afford the joint action to end the piece collectively, something that no individual performer can do on their own. Common and joint affordances thus provide valuable resources for explaining coordination in CFI. In particular, they seem able to explain the articulation of CFI performances. Collective transitions between sequences can occur because common or joint affordances offer the possibility for the group, or at least a significant subgroup thereof, to move together towards a new sequence. 
Mechanisms based on motor representations, that is, common codes for action and perception, and motor simulation, however, have limited explanatory value in the context of CFI. Although both mechanisms have been shown to favor coordination in scripted music performance (Novembre \& Keller, 2014), it should also be noted that these effects are only observed among musicians playing the same instruments, such as the piano, or instruments sufficiently similar to require similar motor repertoires, such as violin and viola, and among musicians playing homogeneous parts, where coordination is mostly a matter of precise synchronization. Now, because of its flexibility, and in particular, of the typical absence of a clear and regular pulse, CFI generally does not have the same demand for precise synchronization of similar behaviors, which limits the explanatory value of these mechanisms. Second, the effects of action-perception couplings in the brain are observed only under a condition of similarity of motor repertoire. However, Bishop and Goebl (2014) showed that the ability of experts to detect audio-visual asynchronies in musical contexts is instrument-specific: expert pianists are better at detecting audio-visual asynchronies in a video clip showing a piano performance than in a clip showing a violin performance, which is further away from their motor repertoire. Whether some mechanisms based on motor representations could be operative between musicians playing instruments associated with different motor repertoires is still unknown. Thus, in instrumentally heterogeneous ensembles, the effects of motor representations for coordination may have a more limited impact. Also, the common use in CFI of idiosyncratic and extended techniques, as well as nonstandard instruments (Canonne, 2019) further limits the possibility that sufficiently similar motor repertoires might be shared among many CFI performers within a group. Thus, mechanisms based on motor representations in the context of CFI might explain, at best, certain types of consolidation involving similar motor behavior.

This review of the possible contributions of each type of mechanism shows that they are diverse enough to account both for some consolidatory and for some articulatory aspects of coordination in CFI. Each type of mechanisms gives at best a partial solution to the problem of coordination faced by CFI performers, so it is not absolutely implausible to think that, combined in the right way, they may by themselves suffice to 
sculpt the segmental forms typical of CFI performances. But this requires more to be said about this mode of combination.

\section{The purely emergent coordination view and its limits}

The view that coordination in CFI can be explained only in terms of emergent coordination has been suggested by Linson and Clarke (2018) who promoted an ecological and embodied account of CFI in which coordination is approached from the standpoint of distributed cognition theories of collaborative creativity, based on Hutchins's famous account of the group operation of a nautical vessel $(1990,1995)$ :

As Hutchings points out, individually skilled interaction with common materials give rise to a loose sense of coordination that does not always require-indeed, may not allow_a "global plan." Similarly, when skilled improvisers share the same broad aim of producing a collaborative performance, their physical and sociomusical interactions with jointly produced musical materials may manifest an emergent sense of coordination that is not rooted in a common view of the performance. (Linson \& Clarke, 2018, p. 60)

Linson and Clarke are right to point out that coordination in CFI cannot be based on the representation of a global collective goal, if that representation is to contain the same amount of information as a conductor score for a scripted musical performance. In that respect, the collaboration of CFI performers towards the rendition of a piece of improvised music is arguably analogous to the collaboration of sailors on a nautical vessel:

In the group performance mode, the sequence of actions to be taken need not be explicitly represented anywhere in the system. If participants know how to coordinate their activities with the technologies and people with which they interact, the global structure of the task performance will emerge from the local interactions of the members. The structure of the activities of the group is 
determined by a set of local computations rather than by the implementation of . . . [a] global plan ... In the team situation, a set of behavioural dependencies are set up. These dependencies shape the behaviour pattern of the group. (Hutchins, 1990, p. 209, quoted by Linson and Clarke, 2018, p. 60)

The limit of this analogy, however, is that the kind of distribution that Hutchins describes relies on a division of cognitive labor delineated by pre-established procedures governing the behavior of each agent, and their interactions with their immediate collaborators. Although this division of labor is not absolutely rigid, as navigators sometimes need to adapt, or even violate some of those procedures for navigation to continue in light of unforeseen events, the distribution of cognitive processes in that context presupposes the existence of a prior division of cognitive labor which is absent in most cases of CFI. Even when groups of CFI establish in advance a shared representation of the music they aim to perform together, individual contributions to the overall result are rarely set in stone (Canonne 2018).

Another model of emergent coordination, involving another form of distribution, sometimes suggested in the literature is that of stigmergy (Borgo 2005, 2007). Stigmergy (Grassé, 1959) is a process of emergent coordination mediated by interactions with the environment. The concept of stigmergy (from the Greek stigma, for sting, and ergon for work) was originally introduced by Grassé to account for the process by which termite colonies build their nest: the configuration of the structure of the nest stimulates the behavior of individuals, which in turn create a new nest configuration providing further stimulation for the behavior of individuals. For example, the pheromones dropped by individual termites leave a trace of their path in the environment, attract other individuals and constrain their behavior. Simple decentralized rules govern the behavior of individual termites, which, at the level of the colony, generate complex pattern of coordination enabling, for example, the construction of sophisticated architectural patterns (Bonabeau et al., 1999).

It may indeed be tempting to hypothesize that CFI performers rely on stigmergic processes, or at least on stigmergic-like processes, in order to coordinate. On this view, CFI performers coordinate indirectly by modifying the sonic environment with which 
they all interact in real time. The analogy with actual stigmergic processes in social insects is, however, limited. It has been argued that complexity in global behavior is correlated with large numbers of individuals, high specialization of tasks and low individual complexity. However, CFI ensembles display complexity of behavior even with a low number of individuals, each having a complex and rather unspecialized behavior, at least compared to idiomatic forms of improvisation. Given the transient character of the sonic environment, it is also much more difficult, if not impossible, to identify cues, as opposed to signals, which may affect the behavior of different performers at different times. As a result, the stigmergic model of emergent coordination is of limited explanatory value.

Although it is clear that some emergent coordination mechanisms are operative in CFI, it is difficult to see how they could be combined to yield the kind of consolidatory and articulatory behavior one observes. Two prima facie promising general models of emergent coordination, distributed cognition and stigmergy, were considered and found of limited explanatory value to account for the full range of complex and flexible behavior displayed by CFI ensembles.

That said, a purely emergent view of CFI need not be tightly associated with the paradigmatic example provided by Hutchins' navigators, nor to the kind of stigmergic processes observable in termite colonies. In fact, there are some reasons to conjecture that a creative segmental form may emerge purely from the interactions between musicians. Canonne and Garnier (2011) proposed a dynamical model of CFI performance. The behavior of each musician is described, at each time, by the signal it actually produces, on the one hand, and an intended signal at each time, on the other. The dynamics of each musician's intended signal is governed by a non-linear differential equation, which takes into account the signals produced by each other musicians, as well the current goal of each musician. This current goal, which is modulated by the cognitive load and the boredom of the performer, governs the way the performer interacts with each other performer, either by agreeing, disagreeing, or agreeing to disagree. Based on these abstract dynamics, Canonne and Garnier ran simulations of CFI performances, showing that the aggregate signal of a collection of interacting musicians displays the segmental form typical of CFI performances. While the model is considerably abstract and 
idealized, it suggests the possibility, at least, that local interactions between musicians are sufficient to account for the articulatory and consolidatory aspects of CFI coordination. What accounts for the coordinated articulation and consolidation of parts is the combination of the three basic modes of interaction, a situation characterized by limitations of attention and a general aversion to repetition of same patterns. To this extent, this model can be taken as describing a blueprint for the combination of basic interaction mechanisms, and more generally as offering a hint towards the possibility of a purely emergent account of coordination CFI.

Yet, although the model does not technically require any collective goal-state, it still ascribes goal-states to individual agents, and crucially relies on the introduction of a teleological ingredient to account for the improvisers' coordination. According to this perspective, it is worth noting that in the model suggested by Canonne and Garnier (2011), even if the emergence of a segmental form is possible when musicians act on the basis of individual goal-states alone, the performances' collective sequences are then, according to the authors, "difficult to produce and/or to discriminate," (p. 38) especially in cases in which more than three musicians interact. On the contrary, when the authors forced their agents to search for symmetrical goals (e.g., if musician A hears that musician B is playing in imitation with them, they will also try to imitate musician B), this resulted in a simulation with a much clearer segmental form. This invites consideration of the possibility that collective goal-states play a role, and perhaps a decisive one, in the coordination of well-shaped CFI performances, in which improvisers aim at being coordinated with each other in a more consistent fashion.

In line with this possibility, we extend the present theoretical account to accommodate a role for planned coordination, in addition to emergent coordination mechanisms.

\section{Locally planned coordination in Collective Free Improvisation}

The idea that collective goal-states (i.e., combinations of individual mental states that collectively represent a goal for a joint action) might play a decisive role in explaining coordination in CFI seems to contradict the assumption that CFI is not based on any pre- 
existing shared plan. A great part of this sense of implausibility, however, might be taken to be an artefact of the contrasting ways in which CFI performances, as opposed to scripted or referent-based performances, are described. It is surely implausible that collective goal-states comparable to those achieved in performances based on conductors' scores or referents for improvisation could be formed in the case of CFI. But this does not mean that other kinds of collective goal-states cannot be formed, in the course of performance, so as to foster coordination in this kind of music. Thus, the general characterization of CFI as referent-free, non-idiomatic improvisation provides no reason for rejecting a priori the possibility that planned coordination mechanisms operate in CFI performances. One way of relying on planned coordination in CFI would be for the performers to form in the course of the performance short term collective goal-states. Those collective goal-states would have to target joint outcomes of the performance that are sufficiently fine-grained for them to make relevant predictions and monitor the extent to which they are confirmed, for at least a short period of time.

\section{Collective goal-states in Collective Free Improvisation}

In fact, the idea that temporary goals are part of the determinants of improvised behavior is present in the first attempts at modeling improvised behavior (Pressing, 1988). Those goals may target strictly individual outcomes (e.g., starting a solo) but also joint outcomes (e.g., the overall texture of the music produced by the group at a given a time). In the latter case, such goals clearly have a basic "ME $+\mathrm{X}$ " structure, defined as goals which, "given how the agent represents her task . . . can only be achieved with the support of X, either another agent or some other force" (Vesper et al., 2010, p. 999). For example, maintaining an interesting texture or ending a piece in an effective way are goals that involve the contributions of others in some way, even though the specific nature of these contributions need not be represented in a collective goal-state. It can thus be conjectured that short-term collective goal-states may guide the coordination of CFI performers during short sections, at least, of a CFI performance.

This conjecture receives some degree of support from recent work in empirical musicology. Canonne and Garnier (2012) asked groups of between two and four 
musicians to improvise freely for ten minutes and then to comment on a recording of their improvisations focusing especially on their thoughts and intentions while improvising. In their comments, the musicians typically described sequences of their performances in terms of opposites: stable vs. unstable; satisfactory vs. unsatisfactory. This indicates a basic conceptual scheme and thus some common representational resources for the formation of goals for the music to be played. Canonne and Garnier further identified five types of reported strategies: (i) stabilization, (ii) wait and see, (iii) playing along, (iv) intensification, (v) changing the framework of interaction. In a related study, Wilson and McDonald (2016) studied how free improvisers in trios represent the options from which they choose to play each time. Post hoc interviews conducted after the recording of free improvisations revealed a similar conceptual scheme. Musicians tended to represent their options, primarily, as either maintaining or changing the music they were performing. Changing it can be achieved either by initiating something new or responding to what has just been played. Responses can be classified, in turn, into three broad categories: adoptive responses, or making contributions substantively similar to those made by another player; augmentative responses, or adopting some aspects of others' playing but diverging from other aspects; contrastive responses, or playing something fundamentally different. The results of the two studies, while superficially different, can easily be integrated. In fact, the strategies of stabilization, wait and see, and intensification, according to Canonne and Garnier's classification, can be seen as subcategories of maintaining, while playing along corresponds to the adoptive kind of response, and changing the framework to the category of change. The resulting classification indicates a basic conceptual scheme for the specification of the content of $\mathrm{ME}+\mathrm{X}$ goals, insofar as they target the properties of the outcome for the whole group and necessarily involve the behavior of fellow performers. The fact that these categories, extracted from participants' reports, recur across musicians indicates that they form a common conceptual scheme, making it plausible that different improvisers adopt similar specific short-term goals.

The contents of such goals are not as specific as the contents of a typical score, but they are specific enough to provide solutions to consolidation and articulation problems, to the extent that they are distributed in such a way within the ensemble as to 
form the structure of a collective goal-state. For example, if all the musicians in the ensemble more or less simultaneously form the goal of intensifying the music, a coordinated intensification of the whole music behavior should ensue, and a consolidation problem will be solved. This might be the case even if the musicians intensify the music in different ways; all that matters for coordination to occur is that the specific ways in which they intensify the music are compatible, where compatibility is defined as follows: $n$ performers in the same group have compatible $\mathrm{ME}+\mathrm{X}$ goals such that the execution of any goal is compatible with the execution of every other goal.

If the compatibility of different realizations of the same generic goal is sufficient to ensure the coordination of a group, then coordination can be reached even when musicians form different individual goals, so long as their executions of those goals are compatible. In other words, performers need not represent the same outcome for the group in the same way; it is enough that they represent different but coherent outcomes for the group that can be brought about together. For example, in a duo, one musician may want to consolidate the current sequence by intensifying the rhythm, while the other intends to consolidate it by intensifying the harmony. Both local goals are compatible to the extent that they give rise to some coherent solution to the consolidation problem (rhythmic and harmonic intensification), although neither musician envisaged that specific solution independently.

While the conditions for compatible goals are certainly weaker than for fully shared goals, it should be clear, in light of the preceding example, how they can contribute to the solution of consolidation and articulation problems. While being weaker, this condition of mere compatibility is however not trivial, as improvisers may fail to form even compatible goals. In the qualitative part of their study, which draws on the first-person comments provided by the improvisers while listening to their own performance, Canonne and Garnier discuss a case in which improvisers clearly had incompatible goals - the flutist playing an energetic intervention with the goal "to produce a quick articulation" and "to avoid a collective sagging" (according to her own report) while the other musicians had the intention of remaining silent to let the flutist 
take a solo ${ }^{2}$. According to the authors, this incompatibility between individual goals led to a striking case of discoordination, "a literal dead end, manifested by an awkward silence" (Canonne \& Garnier, 2012, p. 203).

The divergences between individual representations and preferences that are to be expected in a context as aesthetically diverse as CFI (Pras et al., 2017; Wilson \& MacDonald 2012, 2017) should not lead us to conclude, however, that the task of forming compatible goals is so demanding that they cannot arise during freely improvised performances. For example, Wilson and MacDonald (2017) asked improvisers to use a think-aloud procedure to describe their own trio performances and found that they provided both convergent and divergent accounts of their performance at different points in their improvisations. While Wilson and MacDonald rightly conclude from this that CFI performances can accommodate divergent understandings, even at points "where the improvisation is developing or changing" (p. 140), they also note that, at some points at least, "all members of a trio acknowledged an event or an apparent need for change, but gave varied reasons for this happening, or interpreted the choices of each player differently" (p. 140). This typically describes situations in which improvisers have merely compatible goals; they are ready to change the music produced by the group, even if they have different individual motivations for doing so. And this is enough for a collective goal-state to emerge within the group, and for the musicians to solve an articulation problem. In particular, compatible goals do not require that improvisers have a shared understanding of the events constituting their ongoing interaction, but simply that the goals that guide their behavior have compatible functional profiles.

In this way, the emergence of compatible goals for the joint outcome allows planned coordination to play a role in CFI, as long as such goals are understood as operating both temporarily and locally. This explanation takes for granted, however, that CFI performers simply come to form compatible goals in the course of a performance. This is a non-trivial achievement that requires an explanation.

\section{Coordinating compatible goals}

2

The sound example discussed by the authors (Sound Example 10) can be found here: http://icmpcescom2012.web.auth.gr/proceedings.html, within the media files attached to the paper. 
The problem of selecting a goal for the whole output of the ensemble, so that the goal selected by each is compatible with the goal selected by all others, has the abstract structure of what game theorists call a coordination game (Schelling, 1960). To take an extremely simplified example, suppose that the members of a CFI duo are consolidating a sequence. They reach a point in the music where it would be equally appropriate to change or maintain their behavior, but only if they both do the same thing:

\begin{tabular}{|l|l|l|}
\hline & Change & Maintain \\
\hline Change & 1,1 & 0,0 \\
\hline Maintain & 0,0 & 1,1 \\
\hline
\end{tabular}

Table 1. An example of a coordination game in CFI

This coordination game has two coordination equilibria, and the problem is to explain how both players can converge on the same one. One influential idea introduced by Schelling is that the solution of a coordination problem may come from the salience of some particular equilibrium. Equilibria that stand out, for whatever reason, and which can be expected to stand out to all the other agents with whom one needs to coordinate are called focal points. Where such a focal point exists, the players will coordinate there. An equilibrium can be focal for many possible reasons: it could be perceptually salient, more interesting than others, or suggested by a preexisting convention or an immediate precedent. Here, the affordances discussed above might play a crucial role. While it is unlikely that, given the wide variety of individual repertoires in CFI, salient events such as the introduction of a contrasting material or the serendipitous simultaneity of two attacks can consistently afford identical instrumental actions among the improvisers, they can still afford actions that have a similar functional profile, that is, actions that instantiate similar short-term, abstract goals, such as changing, contrasting, maintaining, initiating or intensifying. In our simplified case, the (change,change) equilibrium may be made focal, for example, by a salient shrieking sound, which everyone in the group is poised to interpret as a potential transition point towards a new sequence. According to 
this perspective, Canonne (2013) found that expert improvisers often tended to treat salient accidents (e.g., a sudden pitched sound in an otherwise noisy context) as opportunities for introducing new materials or ideas. More generally, the author suggests that expert improvisers share the trait of being able to scan their musical environment for events that can be salient for the whole group, and not just for themselves, thus identifying points at which expectations can converge. There is however a questionable idealization in the representation of coordination problems in CFI as one-shot coordination games. Other than in very specific circumstances such as those in which a decision has to be taken by all the performers at a particular time, the coordination of short-term goals is best seen as a process occurring over time, rather than as a discrete event. When this temporal dimension is taken into account, the problem of forming compatible short-term goals can be solved in ways other than betting on which direction to take and hoping that it matches with the one chosen by the others.

A natural strategy for solving dynamic coordination problems of this kind is to rely on distributing the roles of leaders and followers among the members of the group (King et al., 2009); it is easier to coordinate if the problem is reduced to one of following the goals proposed by a leader than aiming to opt simultaneously for the same (or compatible) course(s) of action. Although CFI is hostile to the explicit identification of leaders (unlike many forms of idiomatic improvisation such as jazz, in which some performers are identified as being responsible for leading certain aspects of coordination, such as the rhythm section for rhythmic coordination), it does not rule out the possibility that some performers, not necessarily always the same, take leadership at some points in the performance while following the initiatives of others at other points. For short-term goals to converge over time it is thus sufficient that a majority of co-performers follow a temporary leader.

For this sort of strategy to work, however, it is crucial that performers in CFI not only monitor each other's behavior closely, but also that they find a way to communicate the immediate goals they are pursuing when they take a decision affecting the course of the music on behalf of the whole group.

Communicating local goals 
It is well-known that musical performances, including scripted ones, involve a lot of communication (Williamon \& Davidson, 2002; Seddon \& Biasutti, 2009; Davidson, 2012), particularly through bodily gestures (Bishop \& Goebl, 2018). However, while communicative bodily gestures also occur in CFI, in particular through back-channeling (Moran et al., 2015), their importance might be undercut by the audio-centric, quasiacousmatic approach of many CFI ensembles, in which performers ostensibly avoid looking at each other or even play with their eyes closed. As a result, communication between performers in CFI may be best approached as sonic communication, through the manipulation of the musical sounds themselves.

Of course, given the "floating intentionality" of the musical medium (Cross, 2014, p. 814) and, more specifically, the wide variety of aesthetic representations and social constructions engaged in CFI, such sonic communication remains highly fragile and musical events' meanings are "never straightforwardly translatable or decodable" (Wilson \& MacDonald, 2012, p. 567). In other words, if there is some degree of sonic communication in CFI, it necessarily relies on the pragmatic use of contextual cues and can only aim at conveying highly unspecific content. According to this perspective, Canonne and Garnier (2012) found that the improvisers who took part in their study sometimes deliberately created salient events (interrupting or contrasting sounds) not so much for their acoustical, musical and/or gestural content than for their intentional content, whereby they attempted to communicate to the other performers their wish to modify the interactional structure or musical direction of the improvisation, even if their signals were not deliberately intended to have "a deterministic implication" (Denzler and Guionnet, 2020, p. 26).

Communication processes in CFI are not restricted to sending signals for triggering formal articulations; they may also extend to conveying interactional attitudes to others. Aucouturier and Canonne (2017) showed that improvisers could communicate how they relate to each other within an ongoing situation by manipulating simple interactional features such as the time spent playing simultaneously, the tendency to precede or follow, and the degree of harmonic or spectral proximity. In doing so, they could signal their degree of affiliation (i.e., the extent to which they were aiming to play 
with or independently of the other) and control (i.e., the extent to which they were aiming to lead or follow within the interaction). Such relational communication, while fairly abstract and under-specified, arguably plays an important role in explaining how musicians negotiate articulation and consolidation problems: for example, a musician who hears that their co-improviser plays with a high degree of control might be led to wait for them to take the initiative in suggesting the articulation point for the next sequence; a musician who hears that their co-improviser is playing independently of them might be led to update their current goal; by contrast, a musician who hears that their coimproviser is fully supportive of their musical ideas - endorsing an accompanying stance which acknowledges their every move (Pelz-Sherman, 1998) or displaying in their own playing a moment-to-moment awareness of their co-improviser (Gratier 2008) - might be comforted in stabilizing their own musical behavior, thus opening the way to the consolidation of the ongoing sequence.

The focus in the music psychology literature on verbal communication during rehearsals (e.g., Ginsborg \& King, 2012) and on body gestures in the course of performance can sometimes obscure the fact that musicians are also able to communicate abstract intentions to each other through the very sounds they are playing. Those sonic communication processes nonetheless play a key role in explaining the dynamics of coordination in CFI or, in other words, how improvisers update their own individual goals to form compatible goals.

\section{Coordination smoothers}

In addition to the mechanisms introduced above that directly help performers to move in the direction of the same coordination equilibrium during performance, there are also many factors that can simplify the coordination problems musicians have to face when improvising together, and that our framework needs to accommodate. According to Vesper et al. (2010), from whom we borrow this concept, these coordination smoothers are particularly useful when it is difficult for agents to monitor and/or predict the behaviors of their partners. Given the relatively high unpredictability that generally 
characterizes improvised interactions, coordination smoothers should be particularly important for explaining coordination in CFI.

\section{Shared mental models}

Familiarity between performers, and the ensuing sedimentation of implicit conventions, clearly play a facilitating role. This is often noted in the discussion of improvised music and in particular of the referent-free, non-idiomatic sort. The theoretical framework we have built so far allows us to explain more precisely, however, how familiarity contributes to the improvement of coordination in CFI. Improvisers who are used to playing together may come to form similar representations of the general task of improvising music collectively, involving a shared conceptual repertoire of the various goals it is possible to form, thus reducing the difficulty of coordination problems. Canonne and Aucouturier (2016) view musicians' mental models of the task of freely improvising music with others as mappings between sound-types and action-types, and describe them by asking improvisers to group short samples of typical musical phrases according to the way they would react to them in a free improvisation. They found that improvisers who were used to playing with each other tended to have more similar mental models. The fact that familiar musicians have shared mental models certainly makes the emergence of common or joint affordances more likely, and thus the formation of compatible goals easier. More generally, musicians with similar mental models are more likely to listen to the ongoing musical situation in a similar way, for example by jointly adopting one of the modes of listening to collective sonic activity identified by Savouret (2010) as microphonic (paying close attention to the acoustical qualities of the sounds themselves), mesophonic (paying attention to the musical shapes created by the performers), or macrophonic (paying attention to the aesthetic or cultural resonances of the performers' outputs). While this in and of itself does not ensure that improvisers will listen to exactly the same things, it still increases the plausibility of their entering a state of joint attention.

\section{Shared aesthetic identity}


In a similar vein, improvisers who work together as a group for a long time tend to develop a stable aesthetic identity - a group signature - that functions as a shared frame of reference for the performers (Canonne 2018). The solidification of this aesthetic identity can proceed implicitly, simply as the result of playing together repeatedly, engaging in informal discussions, or socializing between concerts and rehearsals, but also explicitly, by means of verbal negotiation and deliberations about the aesthetic direction of the ensemble. Importantly, establishing shared territory does not completely solve the coordination problem at hand, since the question of how to organize individual and collective musical behaviors temporally remains in its entirety, even within the musical territory defined by the group; nor does it mean that the divergences between the group's representations and interpretations of behaviors are suddenly eliminated (Wilson \& MacDonald, 2012). But it certainly greatly helps the improvisers to coordinate, by crucially limiting the boundaries of the coordination problem and the range of its possible solutions, with certain combinations of actions or musical situations simply falling outside of the scope of the local improvisation culture developed by the group.

While it is not necessary, strictly speaking, for improvisers to have some shared history of playing together or even to belong to the same improvisation community in order to be able to coordinate when freely improvising - after all, the whole point of the Company Weeks festival was precisely to display first-time musical encounters, sometimes even between musicians from different musical traditions (Watson, 2004) - a general explanation of coordination in CFI should definitely take into account the important facilitating role played by those sedimented shared representations and identities, in simplifying the coordination problems at hand, even though they do not by themselves solve them.

\section{Conclusion}

In this article we have offered a comprehensive theoretical framework for CFI, which identifies two key coordination problems that CFI performers face - consolidation and articulation - and organizes the various kinds of mechanisms that contribute to explaining 
how performers identify solutions to those problems. While we acknowledge the role of emergent coordination mechanisms, the view that such mechanisms are by themselves sufficient to explain all there is to coordinate in CFI does not stand close scrutiny. We thus make room in our framework for a specific form of planned coordination involving compatible temporary and local goals, as well as for explanatory factors that simplify coordination problems, rather than solve them directly. While these different elements have been presented separately, it should be kept in mind that they operate together in the course of the performance. What the framework developed in this article ultimately offers is a map in which the elements contributing to CFI have been arranged coherently (see Figure 1).

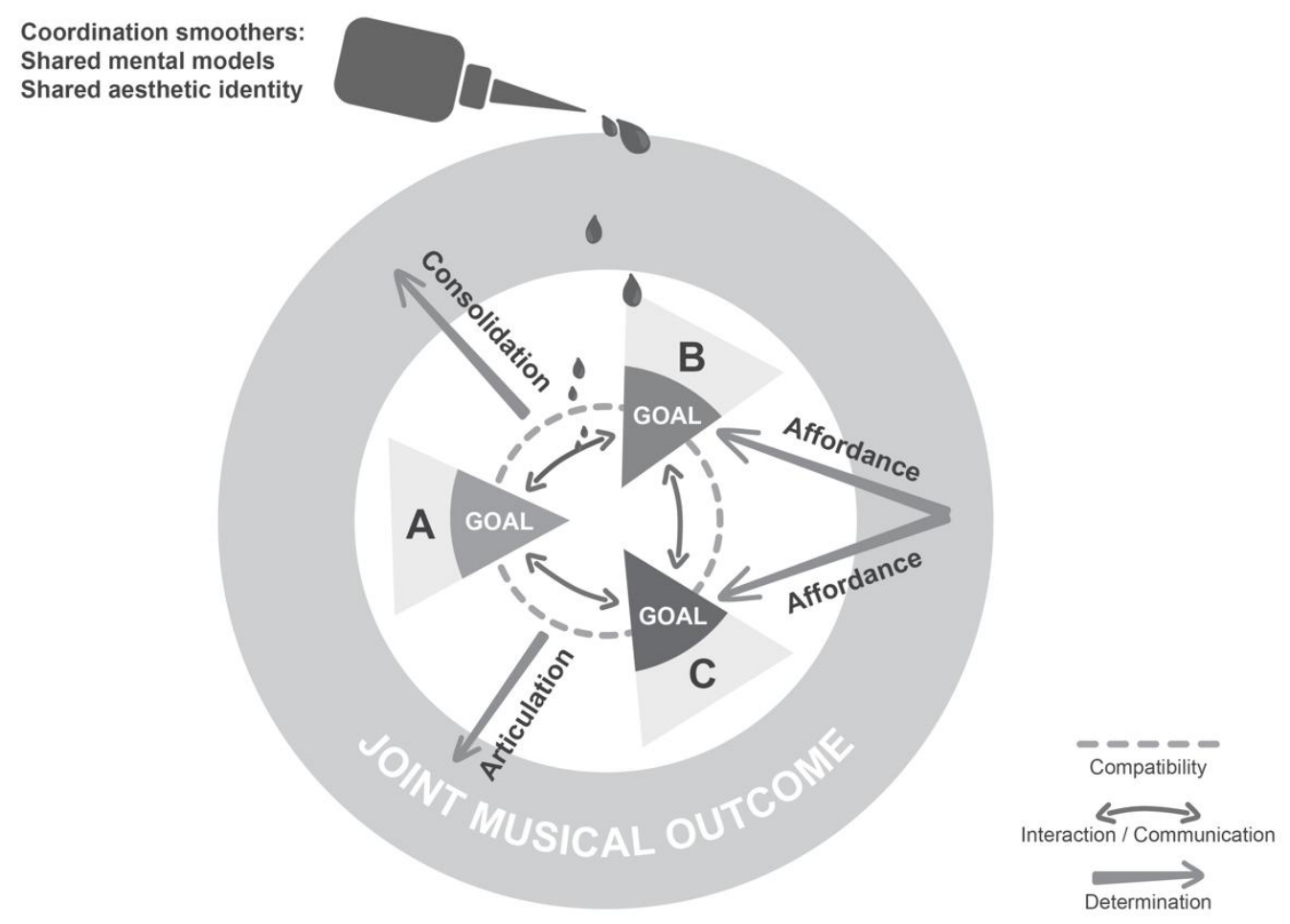

Figure 1. Locally planned coordination in CFI

In addition to integrating the available evidence on CFI, our framework crucially allows for the formulation of new hypotheses that pave the way for further empirical investigations. Three main directions can be suggested here. First, new observational studies could be designed to investigate systematically - for example, using first-person 
reports, either on-line or off-line - the kinds of goal that typically emerge during a CFI, and the conditions for their emergence. Second, if compatible goals are indeed a key ingredient in explaining coordination in CFI, one could covertly prompt improvisers with shared or compatible goals at some point during a CFI and assess the effects of such collective goal-states on the acoustic and temporal coordination of the musicians, or evaluate their impact on the musicians' monitoring and prediction processes. Third, if musicians are indeed engaged in communication processes while they are improvising, one could covertly prompt a single improviser within the group to execute a specific goal and investigate the effectiveness with which they propagate this goal to their coimprovisers, for example by assessing the extent to which their co-improvisers adopt some of the core features of the behavior that was prompted by the investigators.

While this framework is primarily designed to explain coordination in CFI, we believe its relevance extends to other cases of collective improvisation. Of course, referents play a crucial role in explaining how jazz musicians coordinate - to the point that it can sometimes be difficult to tease apart actual interpersonal interactions from the individual's isolated interactions with the script they all share (Pachet et al., 2017) - but jazz musicians also have to face coordination problems that are not easily explained by appealing to such shared referents or to emergent coordination mechanisms alone. To quote Keith Sawyer, jazz improvisers may "stray quite far from the 32-bar song form that initially inspired the improvisation, and by straying from the form, the musicians collectively create a problem for themselves - how will they return back to the 'head'?" (Sawyer, 2003, p. 169); shifts in interactional or metrical patterns, chorus endings, and harmonic suspensions through pedal points and turnarounds all clearly require the formation of compatible goals, entailing non-verbal communication processes. Coordination problems are certainly more or less fine-grained depending on the nature of the improvised practice at hand, but to the extent that musicians' choices and decisions are really made over the course of the performance and not beforehand, the question of how they coordinate with each other should be explainable in terms of the framework we suggested for CFI.

More generally, our theoretical framework also sheds light on the mechanisms that underlie coordination during improvised joint actions outside music, especially the 
kinds of joint action that share some of their core features with CFI such the absence of pre-established shared plans, wide range of possible individual behaviors, and complex temporal organization. While improvised joint actions are generally seen as excluding planned coordination mechanisms, we suggested here that some telic elements, but of a short-term, local nature, might play a key role in explaining improvised coordination. In particular, our framework shows how, in cases of highly flexible and radically indeterminate joint actions, improvisers can form compatible goals through common affordances that will then guide their coordination through short-time planning mechanisms. A comprehensive explanation of coordination in improvised joint action would of course need more work to be fully fleshed out; but we believe that there is still a lot to learn from musical improvisation, at least if we make the effort to pay close attention to its inner mechanisms. 


\section{$\underline{\text { References }}$}

Arthurs, T. (2016). Secret gardeners: An ethnography of improvised music in Berlin (2012-13). [Unpublished doctoral dissertation]. The University of Edinburgh.

Ashley, R. (2016). Musical Improvisation. In M. Thaut, S. Hallam, \& I. Cross (Eds.), The Oxford handbook of music psychology (pp. 667-680). Oxford University Press.

Aucouturier, J. J., \& Canonne, C. (2017). Musical friends and foes: The social cognition of affiliation and control in improvised interactions. Cognition, 161, 94-108.

Bailey, D. (1992). Improvisation: Its nature and practice in music. Verso.

Bailey, D., Balanescu, A., Mackness, V., Robert, Y., and Zorn, J. (1994). DB/AB/YR/JZ/VM part 1 [song]. Company 91, Volume 3. Incus Records.

Bertolani, V. (2019). Improvisatory exercises as a key to analyze group dynamics in collective improvisation: The case of the Gruppo di Improvvisazione Nuova Consonanza. Music Theory Online, 25(1).

Bishop, L., \& Goebl, W. (2014). Context-specific effects of musical expertise on audiovisual integration. Frontiers in Psychology, 5, 1123.

Bishop, L., \& Goebl, W. (2018). Beating time: How ensemble musicians' cueing gestures communicate beat position and tempo. Psychology of Music, 46(1), 84-106.

Bonabeau, E., Dorigo, M., \& Theraulaz, G. (1999). Swarm intelligence: From natural to artificial systems. Oxford university press.

Borgo, D. (2005). Sync or swarm: Improvising music in a complex age. A\&C Black.

Borgo, D. (2007). Free jazz in the classroom: An ecological approach to music education. Jazz Perspectives, 1(1), 61-88.

Burrows, J., \& Reed, C. G. (2016). Free Improvisation as a Path-Dependent Process. In In G. Lewis \& B. Piekut (Eds.), The Oxford handbook of critical improvisation studies, volume 1 (pp. 396-415). Oxford University Press

Butterfill, S. (2017). Coordination Joint Action. In K. Ludwig \& M. Jankovic (Eds.), The Routledge handbook of collective intentionality (pp. 68-82). Routledge.

Canonne, C. (2013). Focal points in collective free improvisation. Perspectives of New Music, 51(1), 40-55.

Canonne, C. (2018). Rehearsing Free Improvisation? An Ethnographic Study of Free Improvisers at Work. Music Theory Online, 24(4). 
Canonne, C. (2019). Élaborer son dispositif d'improvisation: hacking et lutherie dans les pratiques de l'improvisation libre. Volume!, 16(2), 61-79.

Canonne, C., \& Aucouturier, J.-J. (2016). Play together, think alike: Shared mental models in expert music improvisers. Psychology of Music, 44(3), 544-558.

Canonne, C., \& Garnier N. (2011). A model for collective free improvisation. In C. Agon, E. Amiot, M. Andreatta, G. Assayag, J. Bresson, \& J. Mandereau (Eds.), Third international conference on mathematics and computation in music (pp. 29-41). Springer.

Canonne, C., \& Garnier N. (2012). Cognition and Segmentation in Collective Free Improvisation: An Exploratory Study. In E. Cambouropoulos, C. Tsougras, P. Mavromatis, \& K. Pastiadis (Eds.), Proceedings of the 12th international conference on music perception and cognition and the 8th triennal conference of the European society for the cognitive sciences of music (pp. 197-214). Aristotle University of Thessaloniki.

Canonne, C., \& Garnier, N. (2015). Individual decisions and perceived form in collective free improvisation. Journal of New Music Research, 44(2), 145-167.

Clarke, E. F. (2005). Ways of listening: An ecological approach to the perception of musical meaning. Oxford University Press.

Clayton, M. R. (2007). Observing entrainment in music performance: Video-based observational analysis of Indian musicians' tanpura playing and beat marking. Musicae Scientiae, 11(1), 27-59.

Corbett, J. (2016). A listener's guide to free improvisation. University of Chicago Press.

Cross, I. (2014). Music and communication in music psychology. Psychology of Music, 42(6), 809-819.

Davidson, J. W. (2012). Bodily movement and facial actions in expressive musical performance by solo and duo instrumentalists: Two distinctive case studies. Psychology of Music, 40(5), 595-633.

Davidson, J. W., \& Good, J. M. (2002). Social and musical co-ordination between members of a string quartet: An exploratory study. Psychology of Music, 30(2), 186-201.

Davis, T. J., Riley, M. A., Shockley, K., \& Cummins-Sebree, S. (2010). Perceiving affordances for joint actions. Perception, 39(12), 1624-1644.

Denzler, B., \& Guionnet, J.L. (2020). The practice of musical improvisation. Bloomsbury Academics. 
Gibson, J. J. (2014). The ecological approach to visual perception: Classic edition. Psychology Press. (Original work published 1979).

Ginsborg, J., \& King, E. (2012). Rehearsal talk: Familiarity and expertise in singerpianist duos. Musicae Scientiae, 16(2), 148-167.

Grassé, P. P. (1959). La reconstruction du nid et les coordinations interindividuelles chez Bellicositermes natalensis et Cubitermes sp. La théorie de la stigmergie: Essai d'interprétation du comportement des termites constructeurs. Insectes Sociaux, 6(1), 4180 .

Gratier, M. (2008). Grounding in musical interaction: evidence from jazz performances. Musicae Scientiae 12(1), 71-110.

Hadley, L. V., Sturt, P., Moran, N., \& Pickering, M. J. (2018). Determining the end of a musical turn: effects of tonal cues. Acta Psychologica, 182, 189-193.

Hutchins, E. (1990). The technology of team navigation. In J. Galegher, R. E. Kraut, \& C. Egido (Eds.), Intellectual teamwork: Social and technological foundations of cooperative work (pp. 191-220). Lawrence Erlbaum.

Hutchins, E. (1995). Cognition in the wild. MIT press.

Isenhower, R. W., Richardson, M. J., Carello, C., Baron, R. M., \& Marsh, K. L. (2010). Affording cooperation: Embodied constraints, dynamics, and action-scaled invariance in joint lifting. Psychonomic Bulletin \& Review, 17(3), 342-347.

King, A. J., Johnson, D. D., \& Van Vugt, M. (2009). The origins and evolution of leadership. Current Biology, 19(19), R911-R916.

Knoblich, G., Butterfill, S., \& Sebanz, N. (2011). Psychological research on joint action: theory and data. In Psychology of learning and motivation (Vol. 54, pp. 59-101). Academic Press.

Lewis, D. (2002). Convention: A philosophical study. John Wiley \& Sons. (Original work published 1969).

Linson, A., \& Clarke, E. F. (2017). Distributed cognition, ecological theory, and group improvisation. In Distributed creativity: Collaboration and improvisation in contemporary music (pp. 52-69). Oxford University Press.

Loehr, J. D., \& Vesper, C. (2016). The sound of you and me: novices represent shared goals in joint action. Quarterly Journal of Experimental Psychology, 69(3), 535-547.

Love, S. C. (2017). An ecological description of jazz improvisation. Psychomusicology: Music, Mind, and Brain, 27(1), 31. 
MacRitchie, J., Herff, S. A., Procopio, A., \& Keller, P. E. (2018). Negotiating between individual and joint goals in ensemble musical performance. Quarterly Journal of Experimental Psychology, 71(7), 1535-1551.

Moran, N., Hadley, L. V., Bader, M., \& Keller, P. E. (2015). Perception of 'backchanneling' nonverbal feedback in musical duo improvisation. PLoS One, 10(6), e0130070.

Nettl, B. (1974). Thoughts on improvisation: A comparative approach. The Musical Quarterly, 60(1), 1-19.

Novembre, G., \& Keller, P. E. (2014). A conceptual review on action-perception coupling in the musicians' brain: what is it good for?.Frontiers in Human Neuroscience, 8, 603 .

Novembre, G., \& Keller, P. E. (2018). Music and action. In R. Bader (Ed.), Springer handbook of systematic musicology (pp. 523-537). Springer.

Nunn, Thomas E. (1998). Wisdom of the impulse: On the nature of musical free improvisation. Retrieved from http://intuitivemusic.dk/iima/tn_wisdom_part1.pdf.

Pachet, F., Roy, P., \& Foulon, R. (2017). Do Jazz Improvisers Really Interact?: The Score Effect in Collective Jazz Improvisation. In M. Leman, P. J., Maes, \& M. Lesaffre (Eds.), The Routledge companion to embodied music interaction (pp. 167-176). Routledge.

Pelz-Sherman, M. (1998). A framework for the analysis of performer interactions in western improvised contemporary art music. [Unpublished doctoral dissertation]. University of California San Diego.

Phillips-Silver, J., \& Keller, P. (2012). Searching for roots of entrainment and joint action in early musical interactions. Frontiers in Human Neuroscience, 6, 26.

Pras, A., Schober, M. F., \& Spiro, N. (2017). What about their performance do free jazz improvisers agree upon? A case study. Frontiers in Psychology, 8, 966.

Pressing, J. (1984). Cognitive processes in improvisation. In W. R. Crozier \& A. Chapman (Eds.), Cognitive processes in the perception of art (pp. 345-363). Elsevier.

Pressing, J. (1988). Improvisation: Methods and models. In J. Sloboda (Ed.), Generative processes in music (pp. 129-178). Clarendon.

Savouret, A. (2010). Introduction à un solfège de l'audible. L'improvisation libre comme outil pratique. Symétrie. 
Sawyer, R. K. (2003). Group creativity: Music, theater, collaboration. Erlbaum.

Schelling, T. C. (1960). The strategy of conflict. Harvard university press.

Seddon, F., \& Biasutti, M. (2009). A comparison of modes of communication between members of a string quartet and a jazz sextet. Psychology of Music, 37(4), 395-415.

Vesper, C., Butterfill, S., Knoblich, G., \& Sebanz, N. (2010). A minimal architecture for joint action. Neural Networks, 23(8-9), 998-1003.

Watson, B. (2004). Derek Bailey and the story of free improvisation. Verso.

Will, U., Clayton, M., Wertheim, I., Leante, L., \& Berg, E. (2015). Pulse and entrainment to non-isochronous auditory stimuli: The case of North Indian alap. PloS one, 10(4), e0123247.

Williamon, A., \& Davidson, J. W. (2002). Exploring co-performer communication. Musicae Scientiae, 6(1), 53-72.

Wilson, G. B., \& MacDonald, R. A. (2012). The sign of silence: Negotiating musical identities in an improvising ensemble. Psychology of Music, 40(5), 558-573.

Wilson, G. B., \& MacDonald, R. A. (2016). Musical choices during group free improvisation: A qualitative psychological investigation. Psychology of Music, 44(5), 1029-1043.

Wilson, G. B., \& MacDonald, R. A. (2017). The construction of meaning within free improvising groups: A qualitative psychological investigation. Psychology of Aesthetics, Creativity, and the Arts, 11(2), 136-146.

Windsor, W. L., \& De Bézenac, C. (2012). Music and affordances. Musicae Scientiae, 16(1), 102-120.

Wolf, T., Sebanz, N., \& Knoblich, G. (2018). Joint action coordination in expert-novice pairs: Can experts predict novices' suboptimal timing?. Cognition, 178, 103-108.

Wöllner, C. (2020). Call and response: Musical and bodily interactions in jazz improvisation duos. Musicae Scientiae, 24(1), 44-59. 